Please cite this paper as:

Tangermann, Stefan (2005), "Is the Concept of the Producer Support Estimate in Need of Revision?", OECD Food, Agriculture and Fisheries Working Papers, No. 1, OECD Publishing. doi: $10.1787 / 845314770374$

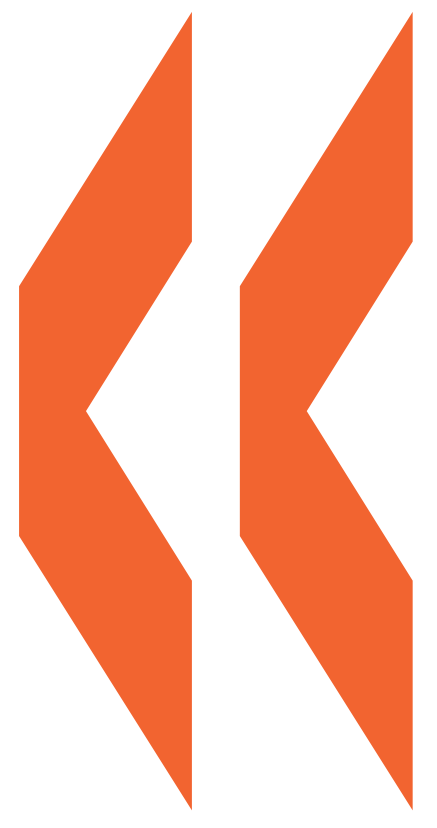

OECD Food, Agriculture and Fisheries Working Papers No. 1

\title{
Is the Concept of the Producer Support Estimate in Need of Revision?
}

Stefan Tangermann

OECD Directorate for Food, Agriculture and Fisheries, Paris 


\section{TABLE OF CONTENTS}

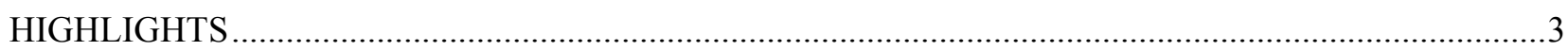

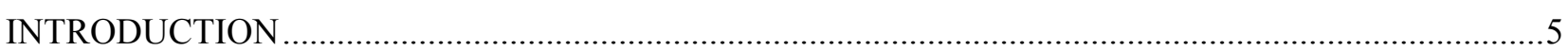

DOES THE PSE PROPERLY REFLECT CHANGES IN AGRICULTURAL POLICIES AND REFORM

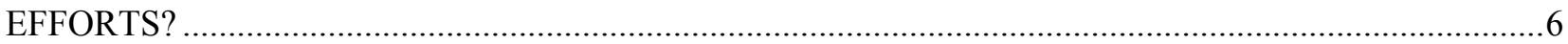

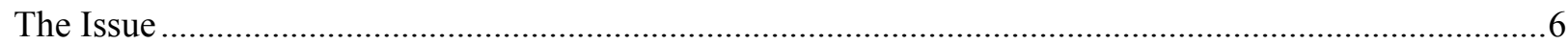

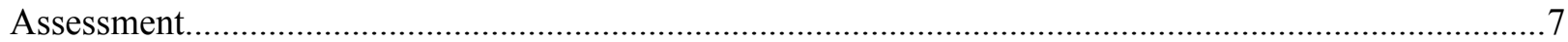

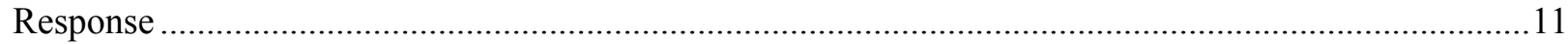

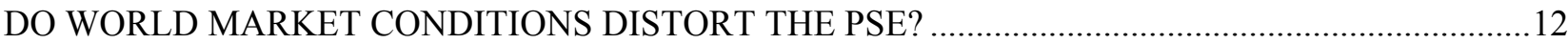

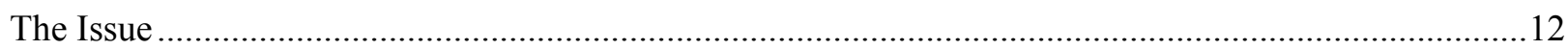

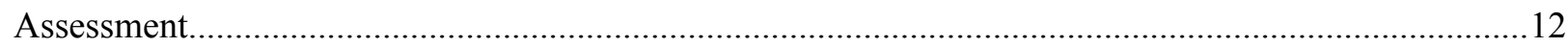

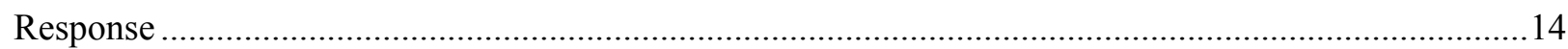

ARE ACTUAL WORLD MARKET PRICES A PROPER REFERENCE POINT FOR THE PSE? ...........14

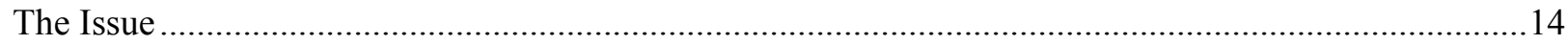

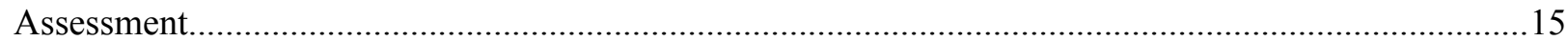

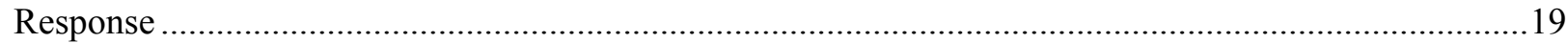

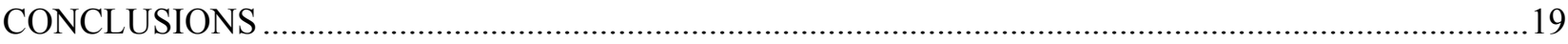

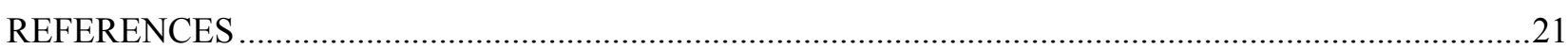

The author gratefully acknowledges support and helpful comments received from colleagues in the Directorate for Food, Agriculture and Fisheries, in particular from Darryl Jones, Wilfrid Legg, and Luis Portugal. 


\section{HIGHLIGHTS}

OECD's Producer Support Estimate (PSE) is the only available source of internationally comparable information on support levels in agriculture. It attracts much attention and receives wide media coverage, not the least in reports that are critical of the way some agricultural policies are pursued. Interpretation of PSE results is not always in line with the underlying concepts, and often too narrowly focused on a few aggregate numbers. Against this background, the PSE approach as used by OECD has been criticized as providing potentially misleading information. This note deals with three central questions raised in such criticism.

1) Does the PSE properly reflect changes in agricultural policies and reform efforts? A country may have revised the nature of its policy instruments by, say, moving from price support to budgetary payments not linked to output, thereby also reducing the trade impact of its policy. However, overall support provided to farmers in that country may have remained constant, thus observers looking only at the PSE level may not give this country credit for its reform efforts.

Where this happens, insufficient use has been made of the information provided by OECD. In OECD work, growing emphasis has been placed on the composition of support from different categories of policy measures, and in particular on the distinction between (a) policies that have strong production and trade distorting effects and (b) measures that have less effects on production and trade. The shares of the different categories of measures in each country's overall PSE are clearly presented, in addition to the PSE level. By making full use of the information provided by OECD, it is possible to assess changes in policies and reform efforts. And by using other analytical tools and the crucial policy information on which the PSE calculation is based, the OECD also provides ample information on policy effects and their changes over time in a variety of publications. However, the OECD is making even more of an effort to communicate relevant information on the composition of policy support, in order to limit any misinterpretation of actual policy developments.

2) Do world market conditions distort the PSE? A country's PSE may vary over time, even if policy settings in that country have not changed. The main reason is that the calculation of the market price support component of the PSE is based on the gap between producer and border prices. When border prices change, due to variations in world market prices or exchange rates, market price support as measured by OECD often also varies, even though nothing has changed in domestic policy settings.

Such variability in measured market price support is an appropriate reflection of policy incidence. Where policy makers explicitly decide to insulate domestic markets from changing world market conditions, they implicitly provide levels of support that vary over time - which does not occur with policies such as fixed tariffs that allow changing world market conditions to be reflected in domestic markets. In evaluating policy it would be wrong to treat such different policies as if they were the same. At the same time, policies with equivalent effects have to be treated in an equivalent way, and it would also be wrong to eliminate border price fluctuations from the measurement of market price support, when this is not done (and has never been suggested) for deficiency payments that cover the difference between a fixed domestic target price and actual market prices. However, here again, OECD is increasing its efforts to communicate PSE results more effectively by pointing clearly to the sources of variations in support levels.

3) Are actual world market prices a proper reference point for the PSE? It has been argued that actual world market prices are depressed as a result of current agricultural policies in the OECD area, and hence that the market price support component of the PSE is inflated. It has been suggested that a preferable approach might be to use equilibrium world market prices that might prevail in the absence of policies. 
While this alternative approach might be of interest for certain types of analysis, it could not possibly serve as an appropriate basis for the policy dialogue that is at the heart of OECD work on agriculture. That dialogue needs to start from an account of policy effort (i.e. an input measurement) before it can proceed to an analysis of policy effect (i.e. an output measurement). The PSE is a measure of policy effort, and the intensity of effort needed to keep domestic prices at given levels clearly depends on actual, not hypothetical, world market prices. Moreover, for policy dialogue among governments, indicators are needed to provide information which is useful in considering the need for policy reform. Indicators based on anything else than actual prices would provide distorted information. For example, if equilibrium world market prices, above actual prices, were used in measuring market price support, then countries that currently do not provide any price support would be shown to have a negative level of market price support, suggesting that they should "reform" their policy by introducing deficiency payments or export subsidies. Also, where deficiency payments are currently provided, for reasons of equal treatment the PSE would have to reflect a synthetic smaller payment rather than actual expenditure - which would not make sense. However, it has to be acknowledged that the aggregate level of market price support for all OECD countries ( $\$ 143$ billion in 2003) must not be interpreted as indicative of the decline in farmers' revenue across the OECD area that would follow an elimination of all such price support globally. Again this is a point where OECD is enhancing its efforts to communicate the meaning of its PSE results clearly, to avoid misinterpretation.

In conclusion, a careful review of the criticism of the PSE does not indicate a need to revise the concepts used by the OECD. However, there are good reasons to make even more strenuous efforts to communicate the PSE results more clearly and effectively, in order to avoid misinterpretation. Communication efforts, by both the OECD Secretariat and Member country governments, may focus on the following aspects in particular:

PSE results not only provide information on levels of support, but also on the composition of policy measures, with some having more and others having less pronounced effects on production and trade.

In order to monitor policy changes and reform efforts, it is necessary not only to look at PSE levels, but also at the changing composition of policies, as reflected in the more detailed information provided by OECD.

OECD uses the information on PSEs, with its various analytical tools, to analyse the effects of policies on production, trade, farm incomes and prices.

Variations in price support (including deficiency payments) over time may result from both changes in policy settings and changes in world market conditions.

It is not correct to interpret the aggregate level of market price support in the OECD area as an indication of revenue loss faced by farmers if policies were eliminated. 


\section{INTRODUCTION}

1. Since the mid-1980s, measurement of support provided by farm policies is one of the flagship activities of OECD work on agriculture. The analytical backbone of this OECD activity is the Producer Support Estimate (PSE). ${ }^{1}$ OECD's annual update of PSEs for its Member countries (and some nonMember economies), published in the "Monitoring and Evaluation" series, is the only available source of internationally comparable information on support levels in agriculture. ${ }^{2}$ Measurement and publication of PSEs have created an unprecedented degree of transparency regarding the nature and incidence of agricultural policies in the OECD area, established a firm base for international policy dialogue on agriculture, and contributed significantly to the formulation of internationally binding commitments on domestic support in the WTO following the Agreement on Agriculture concluded in the Uruguay Round.

2. Given the prominence of the OECD's PSE, it is no surprise that results of this work attract much public attention and receive wide media coverage. However, public usage and interpretation of the figures published by OECD are not always in line with the underlying concepts. Also, the much wider scope of OECD work on policy analysis in agriculture, relying on a number of different analytical tools, is sometimes not taken into account when PSE results are discussed. This may be one of the reasons why governments of some OECD countries, but also academics, have occasionally questioned the validity of some elements of the measurement concept. Concerns have been expressed whether the PSE provides an appropriate and fair impression of the nature of all countries' agricultural policies. The OECD Secretariat takes such concerns seriously, and wants to respond to them in a constructive way, suggesting revisions where they may be required. There is no point in insisting on a yardstick that lacks conceptual validity and hence political credibility. At the same time, it is important that the results of support measurement are communicated to the wider public in a manner that avoids, as far as possible, misinterpretation.

3. Criticism of the PSE has focused on three issues. First, it has been argued that the PSE does not properly reflect changes in agricultural policies and in particular their effects on trade. In this context, concern has been expressed in countries that have engaged in reforms of their agricultural policies by changing the nature of the instruments used, that the PSE does not give these countries sufficient credit for their reform efforts. Second, concern has repeatedly been voiced regarding the fact that variations over time in the PSE reflect not only changes in policy settings but also changing world market conditions and exchange rates. Third, it has been argued that in measuring market price support (still the largest component of support, currently accounting for $60 \%$ of the aggregate PSE for the OECD area), domestic prices should not, as is currently the case, be compared with actual world market prices but with undistorted world market prices that might prevail in the absence of all policies. These three issues are discussed in the following sections of this paper.

1 Originally the acronym PSE stood for Producer Subsidy Equivalent. The conceptual foundation for expressing the incidence of different types of government policy through a subsidy with equivalent effect was laid by Corden (1971). Josling (1973 and 1975) applied this concept to agricultural policies and coined the term Producer Subsidy Equivalent. OECD later changed the name into Producer Support Estimate precisely in order to emphasise the fact that the PSE as calculated by OECD measures all transfers to agricultural producers, rather than the subsidy that would have an equivalent effect on production and trade.

2 For an overview of the conceptual foundations, history and use of the OECD's support measurement, see Cahill and Legg (1989-90) and Legg (2003). The methodology used in PSE work is explained in OECD (2002). For a brief overview of the concept and empirical implementation of the PSE, see OECD (2004a). 


\section{DOES THE PSE PROPERLY REFLECT CHANGES IN AGRICULTURAL POLICIES AND REFORM EFFORTS?}

\section{The Issue}

4. Measurement of support levels provided by agricultural policies, based on the PSE approach, is one ingredient in the dialogue among OECD countries on how to best design and implement agricultural policies, so that they are most efficient and effective in pursuing policy objectives while minimising distortions of markets and international trade. Against this background it is understandable that the question is asked whether the PSE properly captures governments' efforts to reform their agricultural policies. More specifically, concern is expressed that the PSE does not reflect the differing trade impacts of different categories of agricultural policy measures, and hence does not capture the changing nature of agricultural policy regimes in countries that have switched from more to less trade distorting policies. In that context, the comment is also made that the OECD's PSE is not relevant for the trade negotiations in the WTO.

5. One example of such concern has been provided by Haniotis and Bascou (2003). The authors look at the evolution of the EU's policy regime for wheat, finding that as a result of reforms to the Common Agricultural Policy, the support (i.e. intervention) price for wheat has declined significantly since 1992, and that EU tariff protection and export subsidization for wheat have also been reduced noticeably during that period. The authors point out, however, that the OECD's PSE for wheat has remained roughly constant over that period (except for some fluctuations reflecting, as the authors say, mainly variations in the world market price for wheat $\left.{ }^{3}\right)$. The fact that the EU's PSE for wheat remained roughly constant over this period results from the compensation from rising budgetary payments which EU wheat growers have received for the cuts in price support. Haniotis and Bascou (2003) suggest that the switch from market price support to budgetary payments (based on area planted) has greatly reduced the trade distorting effect of the EU's wheat policy, and are concerned that this is not reflected in the evolution of the PSE indicator. They raise what they feel is "the legitimate question of whether the PSE can contribute in the identification of the trade distorting impact of agricultural policies, or whether it has ended up by distorting the very concept it is supposed to reflect".

6. A similar concern is expressed by Rieder et al. (2003) who make reference to Switzerland's PSE for milk. They argue that Switzerland has, over time, changed the nature of its policy for milk (and other agricultural products) by reducing market and trade distorting forms of support, in favour of budgetary payments with less impact on production and trade. Switzerland's milk PSE level, though, has remained relatively constant, thus allegedly not reflecting this change in policy composition. Rieder et al. (2003) propose to move from the current OECD approach to a "weighted" PSE that would not simply add up support provided through different categories of policy instruments, with an implicit weight of one given to each of them. This new type of PSE would use the relative trade impacts of different policy measures as weights in the aggregation. They illustrate their suggested approach by calculating a weighted PSE for milk in Switzerland, using arbitrary weights of above or below one, for policy instruments that arguably have an above or below average impact on trade. This recalculated PSE shows a downward trend, and therefore in the views of the authors reflects better the policy changes that have taken place in Switzerland. Haniotis and Bascou (2003) make a similar point when they say that "the most serious weakness of the PSE is its classification of policies without weighing their trade distorting impact".

3 The issue of the impact of world market price variations on the PSE is taken up in the following section of this paper. 


\section{Assessment}

7. When the PSE is criticized for not being a good measure of protection, or for not reflecting trade distortions and hence not capturing the effects of policy re-instrumentation towards less trade distorting instruments, they are certainly right. The development of the PSE level for a given commodity in a given country (and also of the aggregate PSE for a whole country) does not in itself reflect any changes in policy composition and certainly does not capture any changes in the trade impacts of the policy mix. But then this is not what the PSE level is designed to measure, and it is certainly not what the OECD suggests the PSE actually measures. The PSE simply expresses the level of support provided to producers of that commodity (or all producers in that country), as an aggregate across all policy measures providing support to producers. As the OECD has stressed in its work on monitoring and evaluating policies, the PSE is defined as a measure of the monetary value of transfers from consumers and taxpayers to producers, not an indicator of policy effects on quantities produced or traded.

8. However, the OECD calculates and publishes not only the PSE level as an aggregate of all policy instruments, but also its composition in terms of the different categories of policy instruments used (such as market price support, output payments, input payments, payments based on area/livestock numbers, payments based on historical entitlements etc.). As a matter of fact, in publicizing the results of its support measurement, the OECD has over time increasingly emphasized the composition of the PSE from these various policy categories, and any changes that may have taken place in that composition. For example, for several years the Monitoring and Evaluation reports have contained a graph showing the evolution of the composition of producer support in the OECD (for the graph shown in the 2004 edition, see Figure 1). As of the 2004 edition of the reports, graphs showing the change over time in the composition of producer support in individual OECD countries are also provided. The classification of policy measures along these lines helps readers see whether the structure of policies has changed in a way that may have effects on production and trade. Because of the continuous evolution of agricultural policies in OECD countries, an effort is currently underway to revise the classification of policy measures.

9. Using the PSE in policy analysis, the OECD strongly emphasizes the different nature of various policy categories regarding their impacts on production and trade. In this context, when describing changes in policy composition, OECD has also increasingly made use of the terminology of "market protection" (indicated by the producer Nominal Protection Coefficient, i.e. the ratio between producer and border prices) and "market orientation" (indicated by the Nominal Assistance Coefficient, i.e. the ratio between farm receipts valued at domestic and border prices). ${ }^{4}$ This distinction makes reference to the fact that market price support and payments per unit of output (as measured by the Nominal Protection Coefficient) have different (i.e. stronger) impacts on trade than other policy instruments captured in the PSE. In assessing policy developments, both in individual countries and in the OECD overall, reference is thus regularly and increasingly made to the development of policy composition, with particular emphasis on the most production and trade distorting measures, i.e. market price support, output and input payments. ${ }^{5}$ Beginning with the 2003 Monitoring and Evaluation report, for example, a new triangle graph has been introduced, and one of the three axes ("composition") shows the share of these three policy measures in gross farm receipts, and its change over time (see Figure 2).

$4 \quad$ For example, in its 2003 Monitoring and Evaluation report, OECD states that "long run agricultural policy developments in the EU are characterised by a steady, but modest decline in support, with some improvement in market orientation and a significant reduction in market protection" (OECD, 2003, p. 144).

The 2004 Monitoring and Evaluation Report (“Agricultural Policies in OECD Countries - At a Glance”), for example, finds that in the EU "the long term reduction in the most trade-distorting forms of support and in protection continues in the right direction" (OECD, 2004b, p. 48). 
Figure 1: $\quad$ Composition of Producer Support Estimate for the OECD (Percentage share in PSE)

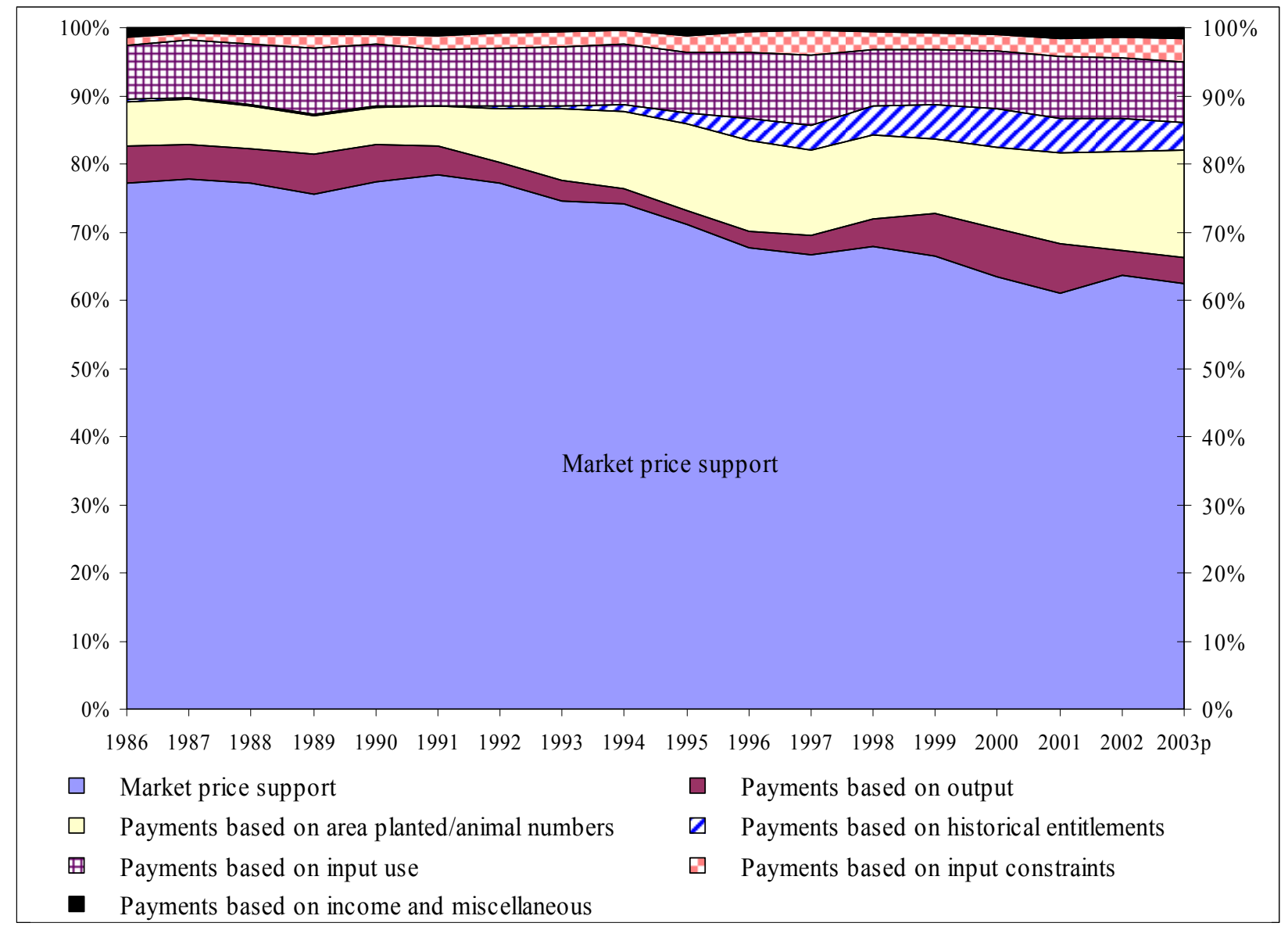

Source: OECD, PSE/CSE data base, Paris, 2004.

10. Based on the information provided by OECD, it is clearly possible to assess the changing nature of agricultural policies in the individual countries covered, including any switches from more to less trade distorting instruments. For example, in looking at the development of EU support for wheat one can easily go beyond a simple description of the \%PSE level and assess the evolution of its constituent components over time, as done in Figure 3. From such information, it can clearly be seen that the share of the most production and trade distorting policy measures in producer gross receipts for wheat in the EU has declined significantly over time. As of the 2004 edition of the Monitoring and Evaluation report (Agricultural Policies in OECD Countries - At a Glance), the composition of the PSE is shown, in graphical form, for all commodities in all OECD countries.

11. Against this background it cannot really be said that the OECD measurement of agricultural support in the framework of PSE analysis provides misleading information. However, two questions remain. First, if different policy instruments have different effects on production and trade, does it then still make sense to add them up to one single number, i.e. the PSE? Second, would it not indeed make sense to calculate a trade-effect weighted PSE, as suggested by some authors? 
Figure 2: $\quad$ Changes in the Level, Spread and Composition of Support in the OECD (Per cent of value of gross farm receipts)

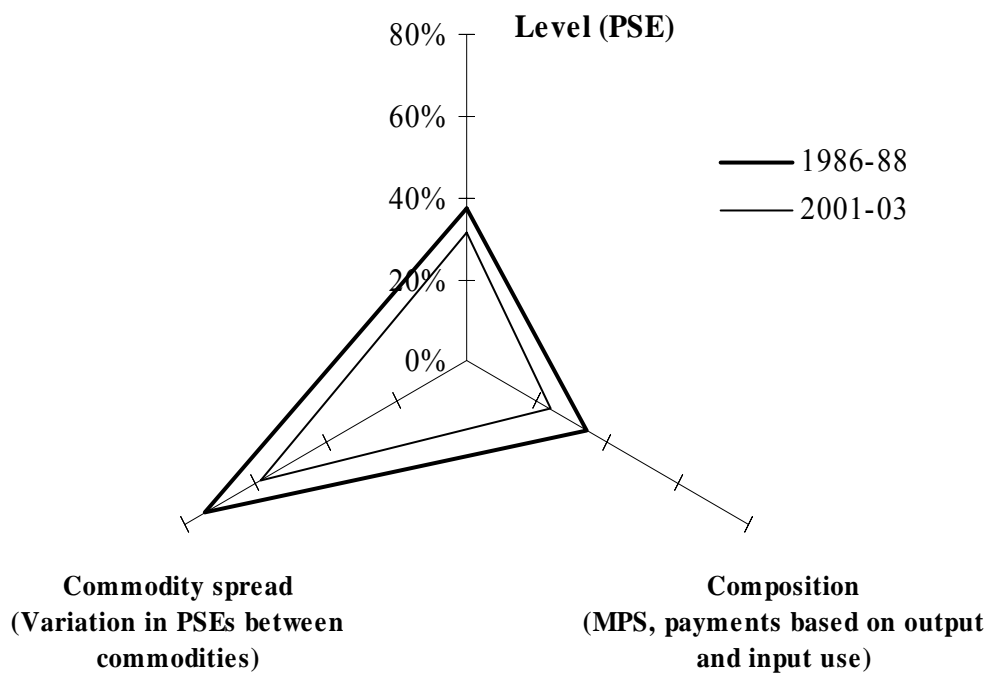

Notes:

1. The level of support is measured by the \% PSE. The composition of support is measured by the share of market price support, payments based on output and payments based on inputs in gross farm receipts. The spread in commodity support is measured by the coefficient of variation of commodity producer nominal assistance coefficients (NAC $p$ ), weighted by value of production.

2. All the axes are on the same scale shown on the vertical axis.

Source: OECD, PSE/CSE data base, Paris, 2004.

12. To question the (unweighted) aggregation of support provided through different policy measures into one common unit, the PSE, on the grounds that different policy instruments have different trade impacts, is akin to criticizing the design of a ruler on the grounds that it cannot gauge temperature. Although PSE information may be the basis for estimating trade impacts of policies, the PSE has not in itself been designed to measure trade impacts - and the OECD has never argued that it does. As said above, the PSE is designed to be an indicator of policy transfers to agricultural producers. There are good reasons for policy analysts to estimate the total value of transfers provided by given sets of government measures. After all, the aggregate value of transfers provided to producers in a given sector is a useful indicator of the overall effort made by governments to shape developments in that sector. ${ }^{6}$ Of course, policy analysts want to know more than this overall effort, and in its policy analysis OECD indeed goes far beyond the estimation of PSEs. But when dealing with any subject it is always useful to begin with a broad overview, and that is precisely what the PSE is thought to provide.

6 At the same time, the value of transfers directed to producers in a given sector may also provide information on the intensity of lobbying going on in that sector. 
Figure 3: $\quad$ EU \% $\quad$ PSE for Wheat and Its Composition

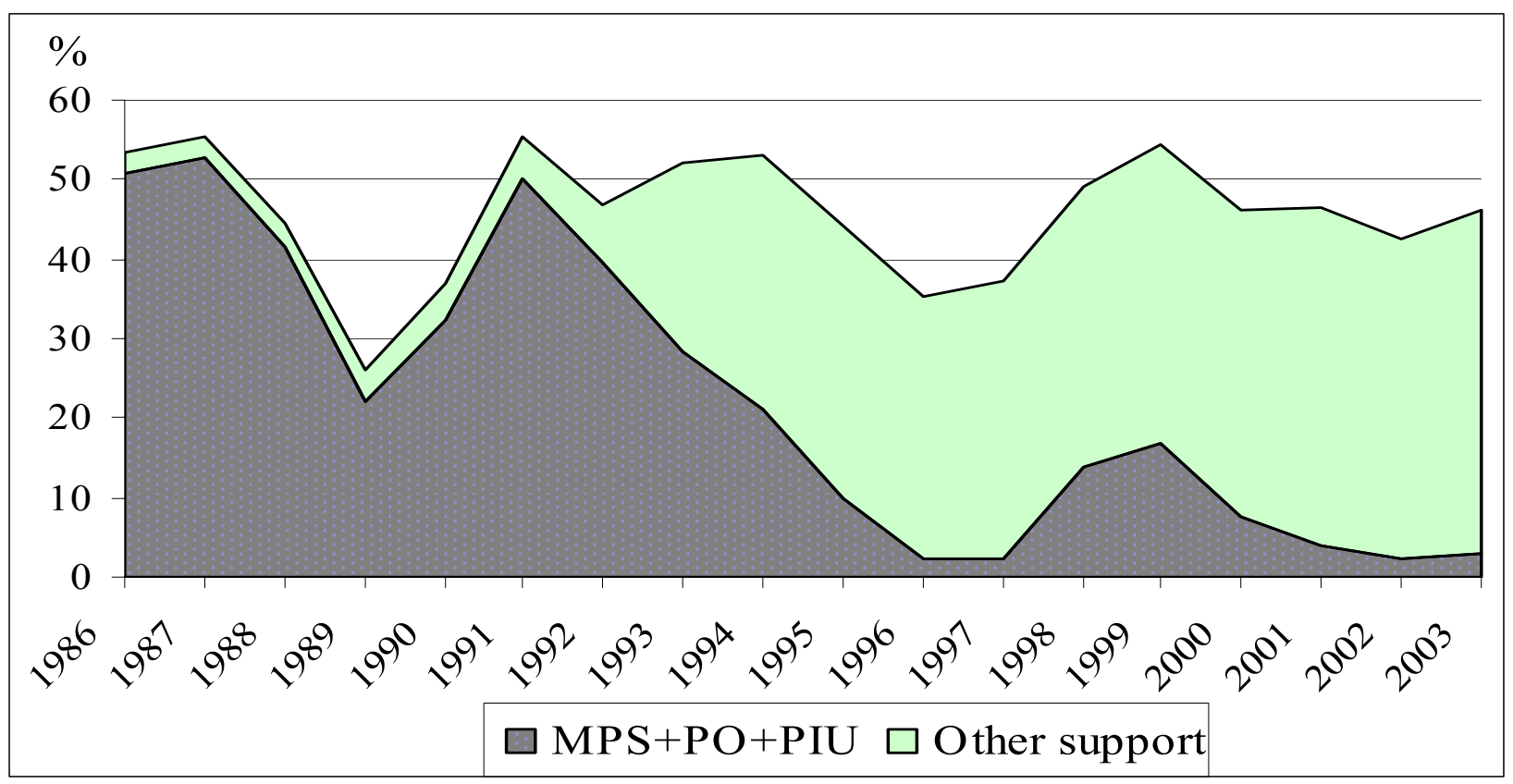

Note: MPS: market price support; PO: output payments; PIU: payments on input use; Other support: all other elements of the PSE.

Source: OECD, PSE/CSE data base, Paris, 2003.

13. The inclination to criticize the PSE on the grounds that it does not reflect trade impacts of policies and does not capture the evolution of policy reform towards less trade distorting policy instruments may be largely motivated by the fact that the PSE has, in the international debate about agricultural policies, sometimes been used as if it were a yardstick of "policy misconduct", an interpretation that OECD has certainly not suggested. Yet, in the political debate, the higher a country's PSE, the more there is a tendency for that country's agricultural policies to be disapproved of, not least by governments of other countries arguing that their farmers are disadvantaged by such high PSEs in other parts of the world. In a way this says that the introduction of the PSE into OECD work has been almost too successful. The PSE has developed a life of its own, independently of how it is used and interpreted in OECD work. And, of course, one can understand that governments do not like to be criticized because of their countries' PSE levels, in particular in cases where they have engaged in significant policy reforms that may not be reflected in the PSE level (though they are, as shown above, reflected in the composition of the PSE). However, it must also be considered that policy reforms towards shifting to less production and trade distorting instruments, in particular when they are also better targeted to well specified objectives, could well go along with a reduction in the level of support, simply because such better targeted policy instruments are more effective than broad based output or input support, and therefore do not require the same high levels of transfers. OECD work on transfer efficiency has demonstrated this. Against this background it is not inappropriate to look, in addition to the PSE composition, at the PSE level provided in assessing progress towards reform.

14. The fact that the PSE is sometimes seen by the public as an indicator of "policy misconduct" also points to another issue. Some parts of agricultural policies may well be pursued in order to provide specific public goods. Expenditure on these policies has a different nature than sector-wide transfers provided to support aggregate sector income. In measuring PSEs, this distinction is not being made. With the current structure of agricultural policies in most OECD countries, that may not yet be too much of a problem. 
After all, more than three quarters of the PSE for the OECD area comes in the form of sector-wide market price support, output and input payments. Nearly another fifth is in the form of equally sector-wide payments based on area planted/animal numbers or based on historical entitlements. In other words, for the OECD area overall, less than $5 \%$ of the PSE is currently in a form that may potentially be targeted to specific public goods. However, in individual OECD countries the situation is somewhat different, and well targeted policies may in the future play a more prominent role in a number of countries. It might then make sense to consider which approaches could possibly be used in order to show more clearly which part of the overall support comes in the form of policies specifically targeted to provide public goods. To some extent these payments to farmers are captured in the PSE, while other transfers are included in the General Services Support Estimate (GSSE). It should also be noted that in presenting the results of the support estimate, the Secretariat now gives more prominence to the PSE and less to the Total Support Estimate (TSE) that adds up the GSSE and the PSE. A further step in the direction of identifying support for public goods can be made by adopting a new classification of policies under the PSE, as is currently being considered.

15. Concerning suggestions to construct a trade-effect weighted PSE, it should be noted that OECD does indeed do a lot of analytical work on the trade impact of different types of policy measures. A large part of this work is based on the Policy Evaluation Model (PEM) to analyse the effects of decoupling farm support from production. In addition, the OECD's agricultural trade model (AGLINK) is also used to analyse the trade impact of policies. The results of these various areas of work have certainly helped to show what the effects are, in terms of reducing trade distortions, when countries reform their agricultural policies. A general insight gained from OECD work in this area is that one is faced with a considerable degree of complexity when assessing the trade impacts of alternative policies. In any case, it is certainly not a trivial matter to assign weights to different policy instruments in different countries, so that their trade effects are properly reflected. If one wanted to go in this direction it would be more appropriate to use a structural model that reflects the effects of individual policy measures and their interaction. As demonstrated by Martini and Dewbre (2004), the OECD's PEM can be employed to convert PSE information into a tariff equivalent with the same effect on production, trade or welfare, and the results clearly depend on the composition of producer support for the product and country concerned. However, to do this on a routine basis for all OECD countries and commodities would go beyond the resources available.

\section{Response}

16. With all this in mind there is certainly no case for discarding the PSE as a valuable overall indicator of agricultural policy developments. However, more effort may be needed to communicate the results of policy monitoring in the PSE framework in a way that avoids misinterpretation. Regarding the issues considered in this section, communication efforts, by both the Secretariat and Member country governments, should concentrate on a number of messages. First, the PSE is not designed to be, and should not be interpreted as, an indicator of trade effects. Second, the PSE contains a wealth of information regarding the composition of policies and their change over time. Third, different categories of policy measures, easily distinguished in the PSE information on policy composition, have different magnitudes of trade impacts, even if these differences cannot be easily expressed in simple numerical weights. Fourth, the changing composition of policies can also be traced to individual commodities, and this can be shown in OECD publications.

17. With regard to longer term developments in OECD's analytical framework, more work may need to be done in order to identify more clearly those policies that are specifically targeted to the provision of well-defined public goods. Also, work needs to continue that will help to understand the different trade and environmental impacts of alternative policy instruments. In this context, PEM analysis is particularly important. 
18. The PSE is a measure of the monetary transfer from consumers and taxpayers to producers provided by agricultural policies, which measures the policy effort in favour of farmers. It is incorrect to interpret the PSE as an indicator of protection or trade impact. Policy impacts on markets, trade and the environment are analysed by OECD through different analytical tools, in particular the PEM. However, the PSE results provide ample information on the composition of support from different categories of measures, which helps to assess the evolution of policy reform. This information will be given even more prominence in the future.

\section{DO WORLD MARKET CONDITIONS DISTORT THE PSE?}

\section{The Issue}

19. Support levels as measured by the OECD in the PSE framework tend to fluctuate over time. This is particularly true for PSE levels of individual commodities. ${ }^{7}$ These fluctuations occur primarily in the market price support (MPS) component of the PSE, a particularly significant part of support making up for nearly two thirds of the total PSE in the OECD area. The calculation of the MPS for a given commodity is based on the gap between the producer price (at the farm gate) and the border price equivalent (adjusted for marketing margins) in the country concerned. The major source of fluctuations in the MPS is the variability of world market prices for agricultural commodities. As world market prices (at the border) and domestic prices have to be expressed in the same currency, another source of MPS fluctuations is variability of exchange rates.

20. Concerns have been expressed time and time again regarding these fluctuations of MPS, and the related fluctuations of the PSE. The point is made that the PSE is supposed to gauge the nature and changes of policy. The PSE, it is argued, should therefore not change if policy settings have not changed. However, even with constant policy settings, the PSE as measured by OECD may well change because of changes in world market prices and exchange rates. The conclusion is then drawn that the PSE does not properly track policy changes because it also picks up the variability of world market prices and exchange rates.

\section{Assessment}

21. There is no doubt that MPS estimates, and hence PSEs, for many OECD countries and commodities often fluctuate significantly over time, and that these fluctuations show a strong inverse relationship with world market prices. In that sense it may well be said that PSE fluctuations reflect the variability of world market prices and exchange rates. However, this does not necessarily mean that the MPS estimate provides a wrong indicator of the nature and evolution of price support policies actually pursued.

22. In looking at this issue it is useful to introduce the conceptual distinction between explicit and implicit components of agricultural support policies. ${ }^{8}$ The explicit component of policy might be considered to be what results directly from policy parameters explicitly set by governments, such as the determination of a support price in domestic currency. The implicit policy component results when domestic policy settings do not adjust to current market developments, say a decline in the world market

\footnotetext{
7 An example of such fluctuations is the development of the EU's PSE for wheat, shown above in Figure 2.

$8 \quad$ The following text is largely based on Tangermann (2004).
} 
price of the commodity concerned. It is only if one considers both the explicit and implicit components that one can capture the totality of actual effects of policies. This is clear if one keeps in mind that the effects of any policy can only be measured against a reference situation, and that the most obvious reference is that of no policy. In the absence of price support policies, the producer price would be aligned with the border price (adjusted for marketing margins), and would therefore move up and down with changes in world market prices and exchange rates. ${ }^{9}$

23. A situation where the domestic support price (and hence the domestic market price) is kept constant over time while the border price (in domestic currency) fluctuates can then be described as one in which the explicit policy component remains unchanged while the implicit policy component varies over time. Thus the total policy effect also clearly varies over time, because it is the sum of the explicit and the implicit policy components.

24. The MPS and the PSE as measured by OECD deliberately and appropriately include both explicit and implicit policy components, because their purpose is to measure all policy transfers to farmers. Properly interpreted, there can also be no misunderstanding of what the MPS estimate yields. Take the case where a country has kept the support price for a given commodity constant between two years, while the border price in domestic currency has declined. The OECD's MPS (and PSE) then shows an increasing level of support between these years. This result is correct. In the absence of market price support, farmers would in the second year have received a price lower than in the first year. Policy, though, prevents this from happening. This simply means that in the second year farmers benefit more (in terms of larger receipts) from the policy than in the first year.

25. Also, there are different policies regarding the pass-through (transmission) of world market changes to the domestic market, and OECD's MPS properly reflects such differences. For example, if an importing country has only a fixed tariff, then its domestic market price moves up and down with the world market price. The OECD's MPS would show a constant price gap and hence no PSE fluctuation (as long as no other policy instruments had changed). ${ }^{10}$ The fact that over time the MPS of this country behaves differently than that of a country with a constant domestic support price is an appropriate reflection of differences in policy implementation. ${ }^{11}$ Equally, a country providing a deficiency payment to maintain a constant domestic target price makes larger expenditures when the border price is low (including due to exchange rate variations), and vice versa. This country then is shown, in the OECD's PSE calculations, as providing a variable level of domestic output payments. Interestingly enough, authors criticizing the variability of the OECD's MPS estimate as not appropriately reflecting policy developments have not gone as far as to suggest that the OECD should, in such cases, not use actual expenditure on deficiency payments. However, as deficiency payments have precisely the same effect on domestic production incentives as an equivalent level of market price support, they need to be treated in PSE calculations in the same way as MPS.

9 In the reality of complex market situations, pass-through of a given change in the border price to the domestic market may take some time. However, this does not change the fundamental point that in the absence of price support policies domestic market prices would fluctuate along with international prices and exchange rates.

10 In this case, the explicit policy component consists of the fixed tariff, and the nature of the policy is such that no implicit policy component can arise. The total policy effect therefore is constant by design, and this is reflected in a constant MPS and PSE.

11 To show such differences is particularly relevant if one considers the well-known fact that policies allowing no pass-through of international market conditions to their domestic markets add to international price variability. 
26. Readers of the OECD's Monitoring and Evaluation reports who are interested in learning more about the sources of annual variations in PSE levels are provided with the appropriate information, through the tables showing the decomposition of changes in MPS into its constituent components. In these tables, changes in MPS can be traced back to changes in domestic producer prices on the one hand and changes in world market prices and exchange rates on the other hand. Moreover, in order to allow for a better understanding of longer run trends in policies, the OECD is considering the utility of providing additional information on policy developments over time, in the form of secondary MPS estimates and PSEs from which short run fluctuations are eliminated through some smoothing method (e.g. trend calculations or moving averages). ${ }^{12}$

\section{Response}

27. As the OECD's PSE approach is appropriately designed to measure all policy transfers, both explicit and implicit, there is no need to change the method of estimating MPS levels. However, in communicating the results of the PSE exercise, more effort could certainly be made to explain short run changes in support levels, based on variations in world market prices and exchange rates, in the presence of less variable domestic support prices.

28. The PSE measures the transfers associated with agricultural policies, including those resulting from keeping producer prices in the domestic market stable while world market prices and exchange rates fluctuate. This is done in an equivalent way for all types of policies that insulate producer prices from market fluctuations. In particular, market price support and deficiency payments are treated in the same way.

\section{ARE ACTUAL WORLD MARKET PRICES A PROPER REFERENCE POINT FOR THE PSE?}

\section{The Issue}

29. By far the largest component of producer support in the OECD area, and thus in many individual OECD countries, is market price support (MPS), provided through policies such as tariffs, export subsidies and domestic intervention buying that keep domestic producer prices above the level prevailing in international trade. OECD measures market price support by estimating the gap between the domestic producer price (adjusted for marketing margins) and the actual world market price at the border of the country concerned, and multiplying that gap by the quantity produced in that country.

30. It has been argued, for example by Doyon et al. (2001 and 2002) $)^{13}$, Rieder et al. (2003) and most forcefully in a recent paper by Oskam and Meester (2003), that this approach yields wrong and misleading results because current world market prices are distorted through policies. ${ }^{14}$ The appropriate approach, it is suggested, would instead be to use those world market prices that might exist in the absence of policies,

12 Illustrative examples of PSE estimates based on trends of world market prices are provided in Tangermann (2004).

13 For a response to the paper by Doyon et al. (2002), see Tangermann (2003).

A different matter of large practical significance is the choice of the appropriate commodity specification for the reference price. OECD invests much effort into this and reviews procedures regularly. For example, the method used to determine the reference price for milk has recently been changed, such that it is now based on border prices of traded processed dairy products. 
sometimes (by Oskam/Meester) referred to as equilibrium world market prices. ${ }^{15}$ For most agricultural products, such equilibrium prices could well be above current world market prices, in some cases by a significant margin (say, 20 or $30 \%$ for the most heavily supported commodities). This is because existing policies in most OECD countries provide extra production incentives to domestic farmers, and discourage domestic consumption. As a result, export supply on world markets is larger, and import demand is smaller, than would be the case in the absence of these policies. Current world market prices are therefore depressed, i.e. below their equilibrium level that would prevail in the absence of policies.

31. The criticism made is therefore that the MPS component of the OECD's PSE, and hence the overall PSE, overestimates the support provided to farmers. ${ }^{16}$ To use a numerical illustration, overall MPS for the OECD area in 2003 was estimated to have been US $\$ 143$ billion. However, the argument goes, if all agricultural policies were removed, then producer receipts in the OECD area would not decline by these US $\$ 143$ billion, but by significantly less, as world market prices would increase as a result of the elimination of policies, and hence domestic producer prices would not drop to the current lower levels of border prices that OECD uses to calculate the price gap. According to this argument, not only the aggregate PSE for the OECD area overall is wrongly estimated, but the OECD estimate of the MPS for each individual country is also wrong, because it should have been calculated on the basis of the equilibrium world market price. For some countries, it is argued, it is not only the magnitude of the MPS that is wrongly estimated, but even its sign. This would hold for those countries whose current domestic prices are above the current, but below the equilibrium world market prices.

32. Overall, it is argued, the PSE provides a grossly inflated impression of the size of policy induced transfers to OECD farmers. In order to avoid this wrong impression of the actual incidence of agricultural policies in the OECD area, it is suggested that the OECD should use trade models to estimate the equilibrium levels of world market prices for all PSE commodities, and use the results as reference prices to be compared with current producer prices. Should modelling not be feasible, or not be accepted by OECD countries, then it is suggested that alternative approaches could be used, for example a weighted average of producer prices across all OECD countries.

\section{Assessment}

33. It undoubtedly has a lot of appeal to argue that world market prices prevailing in the absence of all policies should be used as the benchmark for calculating the price gap on which the MPS is based. After all, there is no doubt that current world market prices are distorted through the very policies whose transfers the PSE seeks to measure. In the measurement of any activity, how can one possibly use something as a benchmark that is directly distorted through that activity? And there is also no doubt that, if all OECD agricultural policies that have an effect on production and consumption were removed, farmers' receipts in the OECD area overall, and in all individual OECD countries would not decline by an amount that is equal to the PSE as estimated by OECD. This point is not new - it has been made in the Monitoring and Evaluation reports from the first edition. Moreover, the agricultural policies of (some) individual OECD countries can be thought of as being, to some extent, no more than a defence against the world market price depression that results from other countries' policies. Looked at from this perspective, the net

15 Oskam and Meester (2003) also appear to suggest that rather than use actual quantities produced and consumed, quantities that would be observed in the absence of all policies should be used in the measurement of MPS. This point is not taken up here, though it could be discussed in the same way, and with the same conclusions, as the proposed use of equilibrium world market prices.

Oskam and Meester (2003) also make the point that the PSE (and CSE) does not represent the policy effect on producer (and consumer) surplus. This aspect is not discussed here as the OECD has never argued that its policy indicators represent welfare effects. 
effect of the transfers provided by these policies to domestic farmers is much less, in revenue terms, than what it appears to be if current domestic prices are compared to current world market prices.

34. Also, the concept of measuring policy transfers not against actual world market prices but against adjusted world prices, with policy distortions taken out from current world prices, is not at all unheard of. For example, in estimating rates of protection, some authors have suggested, or actually engaged in, use of policy-corrected world prices, and the resulting adjusted protection rates for agriculture were generally lower than those resulting from use of actual world market prices.

35. What is the "right" approach in this matter? As in so many cases, it depends on the objective of the analysis. If the objective were to provide an assessment of the global effects of agricultural policies, then use of equilibrium world market prices might well have merit. An analysis of this type might, for example, be relevant if one is interested in calculating and comparing the effects of all agricultural policies in the world (or in a given set of countries, say the OECD countries) with the effects of industrial, energy or transport policies. However, that is not what OECD analysis of agricultural policies is trying to do. OECD is in the business of providing a platform for policy dialogue among its Member countries. One central objective of that dialogue - well established in the OECD's principles - is to see where there might be a reason to consider policy reform. The typical OECD approach adopted in that policy dialogue is to engage in policy comparison across the Member countries (the "best practice" approach). The unit of observation, hence, is the actual policy implemented in the individual Member country, and the question asked is whether that policy is serving the country as well as it could to achieve its objectives (is it effective, efficient and equitable?). In such policy analysis, one first has to analyse the input, i.e. the policy effort made by government, one must then proceed to assessing the output, i.e. the policy effects achieved, and only after this is done one can compare the two in order to evaluate policy performance.

36. In the OECD's approach to policy analysis, the PSE serves to measure the policy effort, while the OECD's modelling frameworks such as the PEM and AGLINK are used to assess policy effects. Measuring the input side of the equation, i.e. policy effort, can only be done by looking at what governments do in actual fact. If a given country intends to keep domestic prices above those prevailing in international trade, the government may, for example, erect a tariff barrier or establish an intervention price. The effort required to achieve the desired domestic prices depends undoubtedly on the level of actual world market prices - the lower they are, the more effort the government concerned must make in order to secure the desired domestic prices. Why world market prices are low is irrelevant for the policy effort required: the lower the world price is, the higher the tariff has to be in order to achieve a given domestic price. If the world price is further reduced as a result of this country's tariff and other countries' policies, the tariff, i.e. the effort, has to be even higher in order to reach the intended domestic price. If the OECD were to measure price support against a hypothetical world price that might prevail in the absence of policies, it would mix up effort and effect.

37. Another issue to be considered, in the context of policy dialogue among OECD countries, is whether the MPS provides useful guidance for policy decisions to be taken in each individual country. From this perspective, too, there is no doubt that the world market prices that might prevail if all countries were to simultaneously eliminate all their agricultural policies are in no way an appropriate benchmark. On the contrary, an "adjusted" MPS based on such equilibrium world market prices could provide completely wrong guidance to policy makers in each individual OECD country. Consider the case of a country with (almost) no MPS in agriculture, such as New Zealand. If equilibrium world market prices were used to calculate New Zealand's MPS, then New Zealand would be shown to make a policy effort to keep its prices low, providing negative price support to its farmers. Viewed from the perspective of a possible need for policy reform, this would suggest that New Zealand should eliminate that negative MPS, by raising its producer prices, for example by introducing deficiency payments or export subsidies for dairy products. This would clearly not be in the national interest of New Zealand (not to speak of the interests of other 
OECD countries). The economic welfare of New Zealand as a nation would be reduced if deficiency payments or export subsidies were introduced and producer prices were raised, because New Zealand's farmers would then expand production beyond the level at which their (private marginal) production costs are in line with the value of their output for the country overall.

38. The same argument, of course, also holds for a country with (high) positive MPS. If this country were to reform its policies such that its producer prices decline to the level of the equilibrium world price in order to eliminate its "adjusted" MPS, then farmers in that country would still receive prices that are above the prevailing world market level. In order to maintain such prices, that country would have to use tariffs and possibly also export subsidies, i.e. it would have to continue to make a policy effort. For a given commodity, this country might then have a tariff, of say $20 \%$, but would at the same time exhibit a zero MPS, suggesting that there is no need to consider policy reform. However, if the country wants to maximize its economic welfare, it should certainly eliminate the tariff and bring the domestic market price down to the prevailing world market level. This is because it continues to make a welfare loss as long the producer price is not in line with the opportunity cost of that commodity for the country overall, represented by the actual world market price.

39. In short, the purpose of OECD analysis of agricultural policy, including measurement of existing support levels, is to measure actual policy effort, and to provide guidance to policy makers in their endeavour to shape policies such that they serve the economic interests of all OECD countries, individually and globally. An indicator such as MPS, therefore, should tell a story about a possible reason to consider policy reform. That story would be completely distorted, and provide wrong guidance, if it were based on prices that do not exist in reality. Equilibrium world market prices that might prevail in the absence of agricultural policies in all countries are, hence, an inappropriate benchmark for national policy pursuit, and by implication they would be a wrong base for the OECD to measure MPS. Moreover, agricultural policy reform is a stepwise process. Existing prices on current world markets are, therefore, a much more realistic basis for considering policy reform than hypothetical prices that might prevail if all policies were eliminated overnight.

40. But what about a slight variation of the theme, suggesting that at least the world market influence of policies in the country concerned should be considered in measuring that country's MPS? In other words, when estimating MPS for, say, the United States, should the benchmark then not be the world market prices that would prevail only in the absence of U.S. policies? Obviously this issue is potentially relevant only for "large" countries, whose policies have an effect on world market prices. For a large country one could argue that the proper basis for considering policy reform is the level of world market prices that would prevail in the absence of its own policies. After all, that is the price level towards which domestic prices in this country would move if this country were to eliminate all its trade distorting policies. However, if OECD were to calculate MPS in that way, it would again not properly measure policy effort. After all, if a country's policies depress world market prices because of that country's size, then the effort to raise the domestic price has to be even higher. This is analogous to measuring the (high) quantity of energy needed to heat a house with poorly insulated walls. Suggesting that energy consumption should be estimated as if the walls were well insulated would not yield a good measurement. Moreover, a serious equity issue would arise if OECD were to assume away domestic country effects on world market prices. The extent to which world market prices would rise with domestic country policy elimination is greater the larger the country concerned (ceteris paribus). If such adjusted world prices were used in MPS calculations, then for two countries with an identical domestic market price for a given commodity, the larger country (say, the EU) would be assigned a smaller (percentage) MPS than the smaller country (say, Switzerland). If the MPS is interpreted as an indicator of the magnitude of needed reform, then this would signal that there is less need for policy reform in large countries than in small economies. Such an approach would certainly not represent a balanced interpretation of the shared responsibility of all countries to reduce distortions of international trade. 
41. Quite apart from these fundamental conceptual considerations, at least three practical concerns also warn against the use of any synthetic world market prices for MPS calculations. First, trade models would have to be used to calculate such world market prices. While much progress has been made in the design and implementation of such models, different models still yield widely diverging results. For a politically sensitive exercise such as estimating policy support, this would mean that all OECD countries would have to agree on the most appropriate model to be used for this purpose - a potentially very difficult proposition.

42. Second, it is not at all clear which countries' policies should be eliminated when estimating equilibrium world market prices. Only OECD countries, because measurement is done primarily for them? All countries for which OECD measures PSEs, including selected non-Member countries for which this is done? Or all countries worldwide? Based on the fundamental reasoning of those who argue for usage of equilibrium world market prices, this would be the most (if not the only) appropriate approach. However, no support measurement exists for most non-OECD countries, and hence the influence of their policies on world market prices cannot be gauged.

43. Third, if one wanted to adjust world prices by the effects of current policies before measuring MPS, then one would, for logical reasons (not to speak of reasons of equitable measurement of all countries' policies), also have to make an equivalent adjustment to the measurement of deficiency payments. After all, if world prices were to rise as policies are eliminated, then deficiency payments (bridging the gap between a set target price and the prevailing market price) would also decline. For that reason, and because deficiency payments have exactly the same effect on domestic production incentives as an equivalent level of price support, adjustments would have to be made not only to the estimated MPS, but also to the expenditure actually made by governments to support producers through deficiency payments. Interestingly enough, though, such an adjustment to deficiency payments has never been proposed by those authors who argue for the use of equilibrium world market prices in estimating MPS. It appears that critics of the OECD's PSE approach concentrate on indicators that are estimated, while they take something that is as "real" as a government payment actually made as a yardstick beyond question. However, such a distinction is not supported by logic and economic reasoning.

44. A different matter is the aggregation of information across all OECD countries. In this aggregation, a potential "fallacy of composition" should be avoided. Even ignoring the transfer inefficiency of price support policies, it would certainly be incorrect to suggest that aggregate receipts of all farmers in the OECD area would decline by the amount of overall MPS as summed up over all OECD countries (\$143 billion in 2003) following the removal of support. ${ }^{17}$ As said above, the actual decline of producer receipts would certainly be less than this amount (and may actually be close to zero - if we consider the fact that revenue in OECD countries with below-average MPS would probably increase if all market distorting policies were eliminated). If all OECD price support policies in agriculture were removed, consumers and taxpayers would not save this sum, as domestic prices in OECD countries would then be higher than current world market prices.

45. Does this mean that OECD should no longer aggregate its support measures across countries? This conclusion is not warranted. However, the appropriate interpretation of the aggregate figure needs to be carefully considered. The aggregate figure should not be interpreted as being a measure of what would happen to farmers' revenues if policies were eliminated, but as a measure of the level of agricultural policy effort made by all OECD countries and hence as an indication of the scope for reforming their agricultural policies. This is an important distinction which may, though, not be easy to communicate to a wider public.

17 It would be even more wrong to suggest that the aggregate MPS indicates the extent by which farm incomes on aggregate in the OECD area would decrease if market price support policies were removed, as rightly argued by Oskam and Meester (2003). 


\section{Response}

46. The conclusion for future OECD practice in estimating MPS is clear: The OECD should continue to use current world market prices at the border as the reference for estimating the price gap with domestic prices in the calculation of MPS. OECD would not measure policy effort properly, and would simply provide wrong guidance to policy makers in Member countries, if it were to use equilibrium world market prices that might prevail in the absence of all policies, or country-specific synthetic world price indicators corrected for the influence of individual countries on international prices. This conclusion is based on the fact that policy dialogue with each individual Member country has to consider information potentially leading in the direction of the policy design that would best increase the economic welfare of countries, individually and globally.

47. It would though be wrong to interpret the aggregate PSE for all OECD countries taken together as an indication of the reduction in receipts that farmers in the OECD on aggregate might have to face if all agricultural policies were eliminated. The OECD has never suggested this interpretation, and efforts are being made to communicate PSE results in a way that avoids such misinterpretation.

48. The PSE is an element of the policy dialogue among OECD countries. As such, it must serve as a basis for considering policy reform in each individual OECD country. It can do so only if the estimate of market price support in the PSE properly reflects policy effort, which requires that it is based on actual prices - and that is the approach adopted by OECD. Usage of synthetic prices that might exist in the absence of policies would send the wrong signals, suggesting, for example, that countries which currently have no market price support should introduce deficiency payments or export subsidies. Moreover, as deficiency payments are based on actual prices, market price support is also appropriately calculated on the basis of actual prices.

\section{CONCLUSIONS}

49. The producer support estimate (PSE) is a highly visible result of OECD work on agriculture. It is used to monitor the nature and evolution of policies that are often very politically sensitive, both domestically and internationally. This means that the PSE receives much attention, including in non-expert audiences. For OECD, this implies that the approaches used in calculating PSEs must meet the highest analytical standards, and, at the same time, the results must be communicated in a way that avoids misinterpretation as far as possible.

50. Given the prominence of the PSE, it is no surprise that concerns are repeatedly voiced over certain aspects of the approach used by OECD. In this context, the present technical note has addressed three issues of a more fundamental nature: (1) Does the PSE properly reflect changes in agricultural policies and reform efforts? (2) Do world market conditions distort the PSE? (3) Are actual world market prices a proper reference point for the PSE? Other less conceptually fundamental, though quantitatively relevant issues such as the appropriate commodity coverage, are not discussed in this paper, though they are considered in ongoing OECD work on PSEs.

51. On all of the three issues addressed in this note, the conclusion is that the approach used by OECD is well founded.

Regarding the proper reflection of policy changes, attention is drawn to the fact that OECD does not only present results on PSE levels, but also makes available ample information on the 
composition of support resulting from different categories of policy measures. Such information on policy composition allows, for example, to see whether countries have re-instrumented their policies such that a given level of support is increasingly provided by measures with less impact on markets and trade.

Regarding the effects of changing conditions on world markets (fluctuating border prices and exchange rates), it is pointed out that such changes do indeed affect the level of market price support provided by policies that insulate producer prices from developments in international markets. As different policy instruments provide different degrees of such insulation, it is appropriate that support levels are shown to be variable where domestic producers are spared the need to adjust to changing market conditions.

Regarding the use of actual world market prices, rather than prices that might prevail in the absence of policies, the point is made that the PSE is conceived to be an indicator of policy effort (i.e. input), and not a measurement of policy effect (i.e. output). Moreover, being an ingredient in the policy dialogue among OECD countries, the PSE must provide an appropriate basis for considering the need for policy reform. It can do so only if it is based on actual prices, because otherwise it would misrepresent the policy effort actually made and send wrong, and potentially detrimental, signals regarding the direction needed for policy changes.

In the context of the two issues relating to the use of world market prices, attention is also drawn to the fact that market price support and deficiency payments need to be treated in an equivalent way. This would not be the case if the calculation of market price support were based on anything other than actual world market prices.

52. OECD work on PSEs would not be appropriately characterized if it were seen as simply generating a set of numbers on support levels. A major element of OECD's monitoring of policy developments is the collection and assessment of information on the nature and implementation of policies in individual countries and of their evolution over time. This information is also used in other analytical frameworks. In particular, much work is done in OECD on analysing the impact that policies have on production, trade and the environment. Such work is based, in particular, on analytical tools such as the Policy Evaluation Model (PEM) and the OECD's trade model AGLINK. In other words, calculating PSEs is only one part of a much wider set of information on agricultural policies provided by OECD. The PSE is no more, but also no less, than one summary indicator, and OECD makes a significant effort to complement that indicator with more specific insights into the nature and effects of policies.

53. The concerns that are repeatedly expressed over the PSE approach used by OECD point to a need for more effective communication about the use of this element in the OECD work on agricultural policy and the appropriate interpretation of the results obtained. There is no doubt that PSE statistics are sometimes misinterpreted, be it deliberately or not. In part this may result from a tendency, particularly pronounced in public media, to use simple, headline numbers. It may, though, also result partly from genuine difficulties in grasping the somewhat complex implications of the policy analysis. With sufficient effort to explain and interpret the results of such analysis properly, it should be possible to minimise misinterpretation and misuse. The OECD Secretariat is certainly determined to continue to engage in more effective communication of the PSE results, and hopes that Member country governments will also contribute to this effort. 


\section{REFERENCES}

Cahill, C., and W. Legg (1989-90). Estimation of agricultural assistance using producer and consumer subsidy equivalents: theory and practice. OECD Economic Studies, No. 13. Paris: OECD.

Corden, W.M. (1971), The Theory of Protection. London: Oxford University Press.

Doyon, M., D.M. Gouin and N. Paillat (2002), Analyse critique du concept d'ESP, estimation du soutien au producteur. Application au secteur laitier. Économie Rurale, No. 272, November-December.

Doyon, M., N. Paillat and D.-M- Gouin (2001), Critical Analysis of the Concept of the Producer Subsidy Equivalent in the Dairy Sector (Dairy PSE). GREPA Groupe de Recherche en économie et politique de l'agriculture, Université Laval, Ste-Foy (Quebec).

Haniotis, T., and P. Bascou (2003), The PSE: Is it Reflecting, or Distorting, the Trade Impact of Agricultural Policies? Contributed paper presented at the International Conference on "Agricultural Policy Reform and the WTO: Where Are We Heading?" Capri, 23-26 June 2003.

Josling, T.E. (1973), Agricultural Protection: Domestic Policy and International Trade. Rome: FAO.

Josling, T.E. (1975), Agricultural Protection and Stabilisation Policies: A Framework of Measurement in the Context of Agricultural Adjustment. Rome: FAO.

Legg, W. (2003), Agricultural subsidies: Measurement and Use in Policy Evaluation. Presidential Address. Journal of Agricultural Economics 54 (2): 175-200.

Martini, R., and J. Dewbre (2004), Tariff Equivalence of Agricultural Support Policies. Paper submitted to the annual meeting of the American Agricultural Economics Association, August 2-5, 2004.

OECD (2002), Methodology for the Measurement of Support and Use in Policy Evaluation. OECD website at

http://www.oecd.org/findDocument/0,2350,en_2649_33773_1_119669_1_1_37401,00.html.

OECD (2003), Agricultural Policies in OECD Countries. Monitoring and Evaluation. Paris: OECD.

OECD (2004a), Agricultural Support: How is it Measured and What does it Mean? OECD Policy Brief. Paris: OECD.

OECD (2004b), Agricultural Policies in OECD Countries - At a Glance. Paris: OECD.

Oskam, A., and G. Meester (2003), How useful are the PSE and TSE measures in determining agricultural support? Manuscript.

Rieder, P., C. Flury and G. Giuliani (2003), Estimation du soutien à l'agriculture: Alternative à la présentation traditionnelle de l'ESP. Document de travail, Institut d'Économie Rurale, groupe des marchés et politiques, Ecole polytechnique fédérale de Zurich. Juin 2003.

Tangermann, S. (2003), Le concept d'ESP: commentaire et résponse. Économie Rurale, No. 276, JulyAugust. 
Tangermann, S. (2004), Agricultural Policies in OECD Countries 10 Years After the Uruguay Round: How Much Progress? In: G. Anania, M.E. Bohman, C.A. Carter and A.F. McCalla (eds.), Agricultural Policy Reform and the WTO - Where Are We Heading? Cheltenham and Northampton (MA):

Edward Elgar. 